\title{
"I found what I needed, which was a supportive community": An ethnographic study of shared information practices in an online cosplay community
}

\author{
By Emily Vardell ${ }^{1}$ (ORCID: 0000-0002-3037-4789) \\ Ting Wang ${ }^{2}$ (ORCID: 0000-0002-1423-4559) \\ Paul Thomas ${ }^{3}$ (ORCID: 0000-0002-5596-7951)
}

Scheduled to be published as: Vardell, E., Wang, T., \& Thomas, P. (2021). "I found what I needed, which was a supportive community": An ethnographic study of shared information practices in an online cosplay community. Journal of Documentation.

https://doi.org/10.1108/JD-02-2021-0034

\begin{abstract}
Purpose - This study explored the information practices of cosplayers, as well as the social norms, social types, and information infrastructure of an online cosplay Facebook group, the Rey Cosplay Community (RCC).

Design/methodology/approach - To better understand individual behavior, the authors made use of ethnographic methods and semi-structured interviews. Observation of the RCC was combined with information gleaned from select participant interviews.

Findings - The results suggest that the RCC can be conceived of as an information community where fans obtain and share information about cosplay costume making. Sufficient and well-organized information and positive community culture greatly help community members make their costumes.

Originality/value - This works serves as a bridge between fan studies and information science research in its exploration of online communities, shared information practices, and creating non-toxic virtual environments. It also lends support to the idea that positivity, respect for community rules, and a tight-knit connection between members play essential roles in building a non-toxic fan and information community.
\end{abstract}

Keywords - Community of practice, Cosplay, Cosplayers, Facebook, Fan studies, Information practices, Online communities, Social media, Social networking sites

Paper type - Research paper

\footnotetext{
${ }^{1}$ Emily Vardell is an Assistant Professor in the School of Library and Information Management at Emporia State University.

${ }^{2}$ Ting Wang is a $\mathrm{PhD}$ candidate and a research assistant at Emporia State University.

${ }^{3}$ Paul Thomas is a PhD student at Emporia State University and a Library Specialist at the University of Kansas.
} 


\section{Introduction}

In modern fandom spaces, one of the more ubiquitous practices is that of "cosplay" (a portmanteau of the words "costume" and "play"), which can be defined as the behavior wherein "people [dress] up and [perform] as characters from popular media, including comics, animated or live action films, television, games, and other pop culture sources such as music videos" (Mountfort et al., 2019, 3). As suggested by Winge (2006), research is an integral part of a cosplayer's task, and as such, many have embraced online social networks as an essential tool for communicating with likeminded individuals the world over and for tracking down needed information (Baruah 2012). Facebook, one of the most significant social networking sites, is such a source, as it provides billions of users with online communities to stay in touch with a social network established offline or to communicate with other individuals with shared interests or concerns (Baker, 2012; Duggan et al., 2015; Smock et al., 2011).

One Facebook-based hub used for the sharing of cosplay-related information is the Rey Cosplay Community (RCC), which is focused on the character Rey from the Star Wars media franchise. In this qualitative study, the authors sought to study this group through an LIS perspective via ethnographic and semi-structured interview methods. It is worth noting that previous studies of similar fan behaviors have been situated in the domain known as "fan studies." While this field has grown steadily ever since the publication of Bacon-Smith's (1992) and Jenkins's (1992) seminal monographs, hardly any of this research has crossed over into the field of LIS (Price, 2016); likewise, while the topic of community information seeking and sharing practices has attracted several researchers' attention (Mansour, 2020; Park, Gu, Leung, and Konana, 2014), only one such study has focused exclusively on cosplayers (a preliminary exploration of another part of this study ([author names omitted for anonymous review] 2020). This article thus zeroes in on the individual and community information practices that members of the Rey Cosplay Community employ when constructing their costumes, thereby linking the world of LIS and the world of fan studies in the process.

\section{Literature review}

While organized fandom has been around since the early 20th century (Duffet, 2013), the modern study of fandom only emerged around 30 years ago, with research that sought to counter the many negative stereotypes about fans and their behavior (Abercrombine and Longhurst, 1998; Booth, 2016). Of these works, Jenkins (1992) is the one often credited with laying the foundations for modern fandom studies and for situating it in the realm of media/cultural/literary studies; other important studies from this time include Bacon-Smith (1992) and Lewis (1992). After these groundbreaking studies, academic studies of fandom began to increase in number. Of the many studies that have been published, several have studied the communication between fans and between fans and authority creators (Kim and Kim, 2017; Soegito, 2019), fan productions (Fazel and Geddes, 2015; Hill and Pecoskie, 2017), and knowledge sharing (Kim et al., 2019).

Hartel (2003) and Stebbins' (1992, 2009) pioneering work in studying serious leisure through the lens of information science opened new avenues for information researchers who had previously focused almost exclusively on scholarly and professional contexts. The study of serious leisure has continued to be an area of increasing interest in LIS research, with Ocepek 
(2018) looking at "everyday experts" (401) and Mansourian (2021) observing that serious leisure can provide a "meaningful journey towards self-actualization and social inclusion" (para. 1). Research studies predicated in both fan studies and LIS are surprisingly rare, despite the two fields having much in common. That said, a number of studies do exist that consider: fan fiction repositories in fan communities (Bullard, 2016), fan fiction collections and management in libraries (Price and Robinson, 2017a), the digital archiving behaviors of media fans (De Kosnik, 2016), and fans' information behaviors in general (Forcier, 2017; Price, 2017; Price and Robinson, 2017b; Price and Robinson, 2021). Studies relating to information behaviors have focused on individuals with a variety of interests, including fans of television (e.g., Forcier, 2017), music (e.g., Vesga Vinchira, 2019), sports (e.g., Joinson, 2000), and gaming (e.g., Nyman, 2011).

The earliest research on fans' information behavior can be traced back to Hart et al.'s (1999) consideration of fan demand for electronic resources and their use of internet platforms. The researchers found that LIS professionals often ignored (both inadvertently and sometimes purposefully) information generated by fans, thereby excluding this material from processes like cataloging or archiving. This vacuum necessitated that fans create their own classification schema (e.g., fan fiction archives, fan Wikis) to manage their own information. Hart et al.'s (1999) research did not attract major LIS attention until Price and Robinson (2017a) studied the attitude of LIS Masters students when discussing the possibility that libraries begin to catalog fan fiction. With the popularity of crowdsourcing sites to generate digital content (e.g., Flickr, Wikipedia), user-generated information systems have grown in acceptance by information professionals, but at this time, research on fans' information practices, including information seeking and content creating and managing, is just being explored (Price, 2017).

Virtual communities, which can be characterized as "groups of people with common interests and practices that communicate regularly and for some duration in an organized way over the Internet through a common location or mechanism" (Ridings et al., 2002) appeared in the last decade of the 20th century (Baym, 2000); in time, cosplayers began to form virtual communities to communicate with each other (Lin, 2016). In these communities, cosplayers build lasting relationships with others through the constant exchange of commonly-valued information, such as personal cosplay experiences, information about upcoming events, advice, and costume-making tutorials (Vardell et al., 2020; Figallo, 1998; Lin, 2016). Due to the discussion and information sharing capabilities, these virtual communities have played a crucial role in cosplay's development (de Zwart, 2013).

According to Ridings and Gefen (2004), individuals join traditional offline groups for a variety of reasons, including a desire: to belong and connect with like-minded people; to form "values, attitudes and behavioral intentions" (para. 7), and to request or receive information. When it comes to virtual or online groups, however, Ridings and Gefen (2004) argue that "information exchange" is the primary reason individuals join; this exchange usually manifests as members asking questions, offering suggestions, and stating their opinions. Similarly, in virtual cosplay communities, research suggests that one of the primary reasons for becoming a community member is to satisfy informational needs about costume making (author names 
omitted for anonymous review 2020). Community members in these groups usually acquire information by accessing tutorials, files, and photos that the community has gathered, or by collaborating with other community members (e.g., by asking questions).

\section{Research design}

This project has its roots in ethnography, which is a qualitative methodology whereby scholars study cultural groups in their "naturally occurring settings" (Brewer, 2000, 6) to come to a holistic understanding of human behavior. The goal of ethnography, therefore, is not simply to record what is going on, but also to explain why that behavior is happening in the first place (Fetterman, 2010; Geertz, 1973; Murchison, 2010). For this project, our "fieldsite" was a digital location, specifically an online Facebook group entitled the "Rey Cosplay Community" (RCC), through which cosplayers communicate with one another and share information, knowledge, advice, and emotions regarding the construction of specific costumes. The RCC Facebook group was selected as the community of focus due to its well-organized resources, its active membership, and the timeliness of the cosplay character (described in the following paragraph). All three researchers are members of this group and announced their interest in studying the group to its admins prior to joining - an idea to which the admins were warmly receptive. Fieldwork commenced in April of 2020 and has lasted to July 2021, meaning that the researchers have maintained a presence in the fieldsite for well over a year. Because this site was a Facebook group this project can be considered an "online" or "digital" ethnography, in the spirit of Hine (2000, 2015) and Murthy (2008).

To supplement the information garnered from ethnographic observation, our findings were triangulated with semi-structured interview methods. Interviews are often an effective way to gain access into the minds of those whom a researcher is studying. By asking key individuals (commonly referred to in the ethnographic literature as "informants") questions about their life, culture, beliefs, practices, and routines, the ethnographer seeks to understand - in the language of the informant - the why of a situation (Brewer, 2000, 63-71; Fetterman, 2010, 51-64). The interviews for this study were conducted with members of the RCC group a few months after the premiere of the Star Wars film The Rise of Skywalker (2019), which stars actress Daisy Ridley as the protagonist Rey. (Of note, while a few studies, namely Wood et al. 2019 and Hendrickson 2018 have explored Rey cosplaying, none have approached this question strictly from an information science perspective, and none have considered the RCC in particular.) Due to the timing of this ethnographic study - immediately following the release of a Star Wars film and during the COVID-19 pandemic - there was a substantial amount of online discussion about creating her costumes. We used purposive sampling informed by our participant observation to identify and recruit cosplayers who had recently completed a costume and were active in the RCC Facebook group (either by posting their own content or frequently responding with guidance for others)._Participants were recruited through Facebook Messenger by one of the researchers who has been a long-time member of the RCC and had an established presence within the community, which has been shown to be a successful strategy in recruiting for fan studies research (Campbell et al., 2016). In total, seventeen RCC members participated as interviewees in the study. 
Through our opening interview question, we determined that our participants represented a range of years spent cosplaying. Six participants shared that they had been cosplaying between half a year to three years, five participants had been cosplaying between four to nine years, and six participants had been cosplaying 10 years or more, with one participant cosplaying for 21 years. Participants were mostly female identifying, with one non-binary participant. Fourteen of the participants were from the United States, two individuals were from the United Kingdom, and one was from Germany. Additionally, the participants were predominantly White. This is an important demographic note, given that a number of scholars such as Stanfill $(2011,2018)$ and Pande (2018) have critiqued the mostly-white and thus racially exclusionary nature of many fan spaces. A full interrogation of this factor is essential in exploring inequalities in fan spaces (both racial and otherwise); however, it is beyond the scope of the present paper.

The interview guide was organized along the following (somewhat chronological) framework: finding, organizing, using, and sharing information, as well as community building (including questions designed to address social norms and social types present in the Facebook group). Interviews with the informants were conducted in English in May and June of 2020 via the video conferencing platform Zoom. Participants did not receive any incentives for participating in the study and were assigned participant numbers to protect their confidentiality. The three researchers coded transcripts of the interviews with an open coding scheme, developing themes as they emerged from the data. These codes were then applied to the remaining interviews to explore community information practices. This article reports on the findings most relevant to the information experiences and practices in an online community.

\section{Findings}

\subsection{Participants' characterizations of the Rey Cosplay Community}

Our study participants viewed the RCC community as a well-resourced (e.g., sufficient image and tutorial resources) and enthusiastic group of people willing to exchange and share pertinent information and costume-related expertise. When individuals outside the community sought to acquire information from participants about how to make a Rey costume, the participants would recommend that they become a member of the community. Despite being an online community, members of the RCC expressed their belief that it felt "real" in the real-world sense. One of the participants told us that the Rey community "has a very genuine feeling. Even though we are all typing, and it is online, it has a much more genuine feel to it than other groups."

\subsection{The RCC as an information community}

As an online group of individuals predicated on locating, cataloging, and sharing information about the cosplay of Rey, the RCC is perhaps best conceived of as an "information community." First defined by the Library Administration and Management Association (LAMA), an "information community" is "a constituency united by a common interest ... [wherein members] cultivat[e] a community of interest around the provision and exchange of information, or knowledge, aimed at increasing access to that information or increasing communication, and thereby increasing that knowledge" (Durrance and Pettigrew, 2002, 82-83). One benefit of information communities is that they often, as Durrance and Pettigrew argue, "exploit the 
information-sharing qualities of the Internet" to effectively and collaboratively reach some goal (2002, 83). This seems to certainly be the case with the RCC: Participant 8, for instance emphasized that "because we [i.e., the Rey cosplayers] have this actual [online] community built up, it makes it easier to share [Rey-related cosplay] information and easier to be a better cosplayer." Similarly, Participant 17 explained that the RCC uses Facebook's digital capabilities to host "files breaking down stuff," while also letting "a lot of people ... come together [digitally] and try and figure the costumes out."

But it would be a mistake to see the RCC as a group based solely on sharing cold, impersonal data about costuming. The individuals in the group, after all, are human beings, who over the years have formed close bonds with one another; as a result, much of the information that is shared also has a deeply personal element. Many of our informants commented on the personal nature of the group, stating that while they initially joined for information access, they stayed because of the friendships they had developed: Participant 5, for instance, told us: "Back in the beginning, I needed something. When I joined the group, I found what I needed, which was a supportive community." Participant 14 noted something similar: "I was grateful for the support and the help that I received, and I've ended up making some good friends off the back of it as well, which is nice." Many participants also explained that they regularly check on the group not necessarily to ask or answer questions about cosplay, but rather to see what their online friends are up to. In this way, what started as a utilitarian way to access and share information has grown into a bona fide social community.

\subsection{Sense of belonging}

Tying into the previous theme, an overwhelming majority of participants expressed a sense of belonging to the Rey costume group. Although there were more than 2,000 members in this group at the time of writing this article, members shared a common interest in Rey's costume and in her character, and everyone was willing to build relationships with each other and share resources. As Participant 15 stated: "Whenever I feel like I'm weird because I do this or [I think,] 'This is not what normal people do,' ... [this group] makes me feel like that I'm not strange or weird for liking this."

When asking why they felt a sense of belonging to the group, participants described that whether an individual is a beginner or experienced, whether the goal for cosplay is for fun or screen accuracy, it was always possible to find the information they needed as someone would almost always be willing to share his/her resources and interests. This led our participants to claim that there was a greater willingness to interact within the Rey group than with other cosplay groups.

\subsection{Diverse information goals}

Different goals for making Rey's costumes could be observed in the RCC and among our participants. For instance, some of the group members are committed to joining the Rebel Legion, a Lucasfilm-sanctioned, international fan club of volunteers who create screen accurate costumes and portray Star Wars characters at hospitals, concerts, sporting events, and more. Those who seek Rebel Legion approval of their costumes strive to use certain fabrics, implement 
specific details, and meet certain standards. In contrast, other cosplayers in the RCC were more casual, with some, for example, hoping to make a simple costume for a Halloween party or for a movie premiere. While many of the RCC's more active members were seeking to join the Rebel Legion, those who were not claimed that they never felt discriminated against; they also agreed that they were equally able to acquire the needed information. As Participant 14 stated:

... It's not a competition ... It's about having fun and building a community ... While there is a lot of Rebel Legion [discussion] concerning getting a costume approved, ... I understand that people are working hard for their craft. This is something they're passionate about, and they love, and everyone is allowed to experience their passion to different levels.

\subsection{Emphasis on screen accuracy}

Fifteen of the 17 participants discussed screen accuracy (i.e., attempting to make a costume as close as possible to the version worn in the film) when making Rey costumes. Some of the participants did not focus on screen accuracy initially, due to their lack of expertise or economic limitations. One of the participants who did not strive to be screen accurate mentioned that she was afraid to share her costume in the group at the beginning, but then she realized that screen accuracy was not a universal goal or the end-all-be-all for everyone after her costume received positive feedback in the Facebook group.

Others strove for screen accuracy despite expertise limitations or economic barriers. These individuals seek to locate specific fabrics, use the right colors, and employ the correct sewing techniques to be as consistent as possible with the costumes in the film; therefore, it took a significant amount of time and money to achieve screen accuracy. Simultaneously, proper preparation, such as making a plan or finding someone to provide support, was necessary before making a screen accurate costume. The RCC was cited many times as a vital node that provided tutorials and resources that assist in constructing a screen accurate costume. Participants shared that the Rebel Legion standards (i.e., a list of required elements for having a costume formally approved) shared in the group often helped improve costume accuracy.

\subsection{Negative attitudes about informational gatekeeping}

Ten of the group members interviewed were vocal in their disdain for informational gatekeeping practices. According to Shoemaker, "gatekeeping" can be glossed as "the process by which the billions of messages that are available in the world get cut down and transformed into the hundreds of messages that reach a given person on a given day" $(1991,1)$; the person(s) responsible for this curation is likewise referred to as a "gatekeeper" (Shoemaker, 1991). While the term has found use in a variety of disciplines, in the specific context of fandom stu dies, it can be more narrowly defined as those practices wherein individuals police the boundaries separating a fandom-related group or identity (e.g., the Star Wars fan community, Rey cosplayers) from

other out-groups; it is common to hear fans justify this behavior by claiming that it is a necessary way to separate the "real" fans from the "fake" fans. 
Among our informants, there was broad agreement that informational gatekeeping is prevalent in the larger cosplay community. What is more, our informants suggested that in this larger community, the practice usually manifests as the purposeful withholding of useful information in contrast to Price and Robinson (2017b) who characterized information gatekeeping as a collaborative endeavor developed to share information and identify experts. Participant 9, for instance, emphatically stated: "Something I've learned in my time cosplaying over fifteen years is that a lot of people are very stingy when it comes to costuming - very elitist." Participant 9 then emphasized this sentiment by giving voice to an imagined gatekeeper: " "if I have something that works for me, I do not want to share it because I want to be the best cosplayer. I want to be the best of this character." A similar technique of expression was used by participant 16, who told us: "I know [fans in] other communities [are] like, 'These are my 3D [cosplay] files! You can't have them! Pay me money!'”

Contra the world of fandom-at-large, the RCC embraces a decidedly anti-gatekeeper ethos, welcoming any and all would-be Rey cosplayers. This ethos was stressed by several informants, including Participant 9, who noted: "I found that nobody in the Rey community [gatekeeps information]. It's nice because everyone shares tips and advice and support and resources so freely. And that's the most helpful thing." As for why this ethos is so prevalent, several participants suggested it was because information sharing makes them feel good. Participant 2, for instance, explained: "Knowing that I can help out somebody else encourages me to share that information with other people instead of just keeping it to myself and see how everybody else helps one another." This was also touched upon by Participant 17: "I like to share ... as much as I can [with the group] because I want to see other people succeed with their costumes." These testimonials suggest that for many members of RCC, sharing information is popular because it staves off elitist gatekeeping while also bringing people joy.

At this point, it is important to note that an anti-gatekeeper ethos is not pervasive because the RCC is some singular, utopic space in and of itself. Instead, it is the result of concerted effort by many of the group's posters and leaders - namely, its moderators — who Participant 15 argued are "very strict about negativity or unsolicited criticism. They'll take that [content] down ... to foster a positive atmosphere."

\subsection{Social types present in the RCC}

The idea of the "social type," which plays an important part in Chatman's (1991) "small-world" theory, refers to the way individuals are defined and perceived in their small group. The role that an individual plays in a small group depends on how the rest of the group sees them instead of their role in a broader environment; for instance, an individual may be seen as a leader within a cosplay-related space (such as the RCC), but they may not be seen as a leader in their "real-life" workplace (Pendleton and Chatman, 1998).

Of the participants in our study, two were both RCC group administrators and Rebel Legion judges, and 15 were standard group members who lacked administrator privileges in the Facebook group. The Rebel Legion is a fan organization whose members create screen-accurate replicas of the clothing worn by characters from the Star Wars series (History of the Rebel 
Legion, 2015). To determine membership and costume quality, the Rebel Legion makes use of judges, who review fan-created costumes against a set of criteria. Most of the participants whom we interviewed identified the official group administrators (many of whom also serve as Rebel Legion judges) as the group leaders, because the administrators were more experienced in making Rey costumes, more active in the group, more willing to help other group members and make suggestions, more willing to spend time collecting and organizing relevant information, and were responsible for managing the order of the group. When we asked the participants if they or other group members would consider themselves to be leaders in the group, most dismissed the idea, citing their lack of appropriate resources/experience or by noting their lack of official authority.

The two participating group administrators explained that their responsibilities as administrators were to research, collect, and organize information and resources to help other group members start and complete their costumes; caring for group members when they met frustrations; maintaining order within the group; and ensuring the safety of members within the group. Administrators' descriptions of their responsibilities echoed the criteria used by group members to determine who the group leaders were-exemplifying what a social type looks like in the context of a cosplay Facebook group.

\subsection{Atmosphere of support}

When asked about the RCC's dynamic, 12 of our 17 informants used the adjective "supportive" (or a variant thereof) to describe their experiences with the group. A common claim was that the group was supportive of cosplayers regardless of past experience. Participant 2, for instance, said that the RCC members "are very supportive of each other no matter how little into the process you are, or whether you've been doing it for years." Likewise, Participant 5 lauded the group for "encourag[ing members] no matter where [they] are in [their] cosplay journey. They're just supportive." While everyone in the RCC is free to offer advice and share resources as they see fit, there is a distinct emphasis on helping members succeed. This general attitude seems to be intrinsically tied to the group's disdain for gatekeeping practices, as our informants often contrasted the group's supportive nature with other cosplay groups that are more guarded about their cosplay information or are more willing to criticize cosplay newcomers.

\subsection{Beliefs about community changes}

When asked if they had noticed any changes in the Rey group, some participants argued that they had perceived no changes during their time in the group; the RCC members, these participants argued, were as welcoming, supportive, communicative, and intimate as they were when they had joined the group. Others believed that the release of the new movies had prompted more people to join the group, and by extension led to an increased number of posts about new costumes and cosplay activities. Also, some participants, such as Participant 8, described the group changes caused by the development of technology:

The Rey Facebook group when it had first started, it was an unknown territory, because we didn't have all the files and resources that we do now. I'm pretty sure that Facebook also didn't allow you to do as much that you can now to have the search options ... I could 
go on Facebook Rey group right now [and] search for a specific task ... It shows how much that technology grown alone and how much it's easier to find that information here.

\subsection{Unhelpful information}

Our informants were asked if they had encountered any information practices that they explicitly found unhelpful, and their answers can be sorted broadly into three groups. The first category of unhelpful information is misinformation or ambiguity. Frustration with this type of "information" was perhaps best expressed by Participant 1, who told us that they "hate it when someone gets into the group and gives misinformation about where to get materials or things that we accept as judges for Rebel Legion. ... [These people] haven't put in the time yet at all to even understand the costumes, and it throws off other people." Participant 1's disdain for misinformation is perhaps not that surprising. After all, the RCC is predicated on collating and sharing correct information about Rey's costuming; spreading misinformation about that very topic is thus logically the antithesis of the group's mission.

The second category of unhelpful information was unsolicited feedback. According to Participant 17, "The only thing that I find to be not helpful ... [is when] you're proud of something and you're putting something out there [online] and someone comes in and is overly critical. ... You're not looking for criticism and they come in with that." A general disregard for unsolicited feedback was also brought up by Participant 6, who argued that "giving feedback when the person doesn't really want feedback" was seen as a violation of the group's positive ethos. Participant 6 further stressed that if a cosplayer "want[s] feedback [they] always should actively ask a question." In other words, the explicit presence of a question is the social cue that an RCC member is interested in constructive criticism.

The final category of unhelpful information was unnecessarily critical comments and ad hominem attacks (that is, comments that, unlike those discussed in the preceding paragraph, are made in bad faith to hurt or offend). Participant 14, for instance, told us that being "rude" or "nasty" to anyone was not seen as constructive, and Participant 8 explained that costume "bashing" was a violation of the group's main rule about being "respect[ful] to everyone else." Participant 12 echoed the views of P8 and P14 by agreeing that "saying bad things about people's costumes" was unhelpful, but they also offered the following caveat: "I've never seen that happen, because it's all just a super positive community."

\subsection{Hurdles and solutions}

All seventeen of our informants emphasized that overcoming informational gaps or "hurdles" (cf. Dervin, Foreman-Wernet, and Lauterbach 2003) was paramount to their joining the RCC. Three of the most talked about hurdles were locating reliable reference images, determining the sort of material (e.g., fabric) out of which a certain costume was made, and managing time. Regarding the former issue, there was widespread agreement that a lack of good quality reference images made the creation of a costume difficult in some cases and impossible in others. Consider the words of Participant 4, for instance, who contended that "one of the [biggest] challenges was figuring out how to make [a costume when] you don't have a clear image" of the original outfit. Regarding the issue of fabric identification, perhaps Participant 6 said it best 
when she told us: "The third and second time [I watched The Rise of Skywalker, I] was like, okay, let's look at the fabrics. What could that be? Is that linen?"

The specific solutions that our informants sought out to overcome these information hurdles were as varied as the hurdles themselves, but almost everyone whom we interviewed agreed that the RCC Facebook group undoubtedly played an integral role in surmounting these obstacles. When discussing the aforementioned issue of reference images, Participant 4, for instance, told us that when starting the construction of a new Rey costume, she always begins "by looking at the references people were starting to share in the [RCC] group," adding that the "Rey community [comprises] people who analyze [the photos], and they will find every detail." In overcoming issues with fabric identification, Participant 6 likewise told us: "I look up the character groups on Facebook. They're a very, very big help for me. I asked around about the costume. Like, 'What fabrics did others get? What did people have success with? Can I get that [fabric] here or in a local store? Do I have to order this? Is it hard to order?'”

\subsection{2 “In Real Life” ("IRL”)}

Our interviews revealed that group members often seek and share cosplay information "in real life". For instance, cosplayers obtain fabric from craft stores (one participant noted that craft store employees' advice was occasionally incorrect); borrow books on patterns from local public libraries; take photos of costumes on display at movie premieres and Disney parks for details; acquire skills and suggestions from family members or real-life friends; and communicate with other cosplayers at Comic-Con events.

Real-life experience impacted participants' cosplay journeys and the way they communicated within the RCC itself. Participant 1, for instance, explained: "I think that's a really important part of cosplay - helping other people. ... I was a library assistant for many years. That was part of my job: researching [and] collecting information for people. It's just part of what I enjoy doing to make others' life easier." Conversely, the experiences in the group also influenced group members' real-life experiences. One participant shared her experience with dyeing costume parts, which led to her thinking creatively in her job: "I had a client who was thinking about getting a new slipcover for a couch or a chair... I told her what she could do is dye it, [and she would] not have to spend $\$ 300$ on a new one."

\section{Discussion}

Several studies have suggested that individuals - regardless of education, financial status, or occupations - often struggle in recognizing, expressing, and meeting their needs for community information (Chatman, 1996, 2000; Dervin, 1976; Savolainen, 1995). There are numerous cultural, financial, and geographic barriers that prevent people from locating pertinent information, and for cosplayers, one such barrier is likely a sort of social stigma; after all, only three decades ago, it was a common view in groups outside of fandom that cosplay and other fan behaviors (e.g., writing fanfiction, drawing fanart) were psychological symptoms of some larger dysfunction that could lead participants to sexual deviance, violence, drug abuse (Jenson 1992; Kinsella 2000), and other acts of "exotic obscenity" (Chen, 2007, 14). As a result, fans and fan 
culture have often been marginalized by mainstream society, which further exacerbates the difficulties fans have in finding the information they need.

That being said, cosplay does appear to be amidst a sea change. According to numerous scholars, fan culture is a force that in the last few decades has grown to become a social and cultural phenomenon, especially in East Asia and the West (Wilson and Toku, 2004; Chen, 2007; Jenkins, 2007; Booth, 2016; Click and Scott, 2017). Hill (2017), in particular, has argued that the ubiquity of select pop cultural media franchises in the last few decades has increased the public's understanding of fandoms and fan behavior, thereby making fandom itself an "ordinary aspect of life in the industrialized world" (3). The same idea about the increasing popularization of fan behavior was raised in the current study. Participant 1 , for instance, stated that when she wore her costume in her neighborhood, her neighbor remarked "nice cosplay." Because her neighbor (who otherwise showed no knowledge of fan behavior) knew the correct word for what she was doing, the participant argued that this was evidence that fan culture is becoming more mainstream.

With the development of the Internet's potential to provide greater access to information (Durrance and Pettigrew, 2002; Pettigrew et al., 2002), cosplayers have eagerly turned to online information communities to converse with individuals who share their interests. Communities like this, such as the RCC, help members: access information that is otherwise hard-to-obtain and/or high-quality (e.g., information that is "more current, more comprehensive, better organized," Durrance and Pettigrew, 2002, 98); contact reputable information sources (e.g., the admins of the RCC, people who post regularly); and decrease "transaction costs" by saving users time and money (Durrance and Pettigrew, 2002, 98). In the current study, participants affirmed that the RCC filled information gaps and became one of their main sources for cosplay-related information.

Several participants in the study expressed their sense of belonging to the community, with many explicitly citing the information and/or support provided to them-regardless of their own skill level or expertise - by the more knowledgeable RCC members as the reason for this feeling. This connects directly with previous research that suggests the main reason for seeking and sharing information within a community is so that community members can contact those with expertise (Christensen and Raynor, 2003; Lampel and Bhalla, 2007). Additional research has suggested that individuals share information in a community to: engender community via altruistic assistance, help achieve collective goals, ensure that the community continues into the future, confirm their own knowledge about a given subject, and establish a sense of friendship via empathetic and reciprocal behaviors (Blanchard and Markus, 2004; Constant et al., 1994; Hall and Graham, 2004; Lakhani and von Hippel, 2003; Mansour, 2020; McLure \& Faraj, 2000; Preece, 1999a, 1999b; Wasko and Faraj, 2000). As it so happens, when asked why they sought and shared costume information in their Facebook group, the RCC members whom we interviewed cited almost all of these factors as driving reasons. This suggests that when building an information community, information exchange is but a single aspect of the community's foundation; equally as important is the establishment of socio-emotional connections between the community members (Feng et al., 2003; Pigg, 2001). 
In certain online environments, fan communication has become increasingly toxic (Duffett, 2013; Jenkins, 2006; Proctor, 2017; Scott, 2019); this is largely due to the relative anonymity provided to users as well as the "minimiz[ation] of authority" (Lapidot-Lefler and Barak, 2012; Suler, 2000). Several articles on fan behavior have also noted that certain fan bases develop a sense of self-superiority (Di Placido, 2017; Gaudette, 2018; Stokel-Walker, 2017), believing that they alone have a "deep" understanding of their media object of interest. This mix of ownership, protection, and superiority leads them to become gatekeepers (Evangelista, 2019; Price and Robinson, 2017b; Stokel-Walker, 2017). The Rey Costume Community members who participated in this study also discussed with us toxic fan communication and gatekeeping behaviors, such as refusing to share information in other costume making groups or demeaning others because of the quality (or perceived lack thereof) of their costume. However, our informants were uniform in their belief that these behaviors were absent in the Rey Costume Community itself. This may be attributed to positive community rules, emotional connections between members (Mansour, 2020), the community members' consensus regarding a rejection of toxic fan behavior, and the management of negative behaviors within the community by administrators.

Instead, participation in Rey cosplay and in the RCC Facebook group was associated with an increased amount of positivity, confidence, and self-esteem. For instance, participants explained that they were more willing to wear a wig to address medical hair loss, use cosplay as a way to work through addiction recovery, employ creative approaches to work, and learn leadership and communication strategies that inform workplace behavior. As Participant 2 summarized:

What I've learned the most is the fact that anything is possible if you set your mind to it. I think I went in with the mentality that I was just in the Facebook group, and I would just look at people's posts and stuff, but I wasn't really going to partake... Taking the time to actually sit down and put my mind to it, and go through the steps and everything, I've learned that it's not as difficult as it may seem initially. I think with each new challenge that encourages me to want to do more.

\section{Limitations and Future Research}

The semi-structured interviews for this study occurred during the early months of the COVID-19 pandemic, which may have impacted the participants' costume making or information behaviors, thereby biasing the findings and conclusions of the project. Second, the study participants were all females, and therefore, these results may not be representative of the behaviors of male and nonbinary/genderqueer cosplayers. Finally, this study discussed a small part of the wider fan virtual community; as such, these findings do not necessarily apply to the entire fan community. To overcome these issues, researchers could conduct further interviews at different times and with cosplayers in other online communities to reveal if the current study's findings are more widely universal.

\section{Conclusion}


Despite cosplay being a visible fan practice predicated on researching, collecting, and sharing costume-related information, very little research has been published that considers cosplay through the lens of information science. This study has attempted to fill this hole in the literature by ethnographically exploring the information practices of the Rey Cosplay Community (RCC). Of course, this Facebook group is only one of many fan spaces focusing on cosplay, but the present study - which conceives of the RCC as a complex information community, whose members employ myriad information practices and behaviors to create costumes - suggests that other cosplay communities (and fan spaces in general) are likely ripe for informational analysis.

Another important element of this study is the observation that general group positivity, a respect for community rules, and a tight-knit connection between members seems to strengthen an information community as a whole. This observed relationship between general group positivity and the overall state of an information community is notable, especially given the rise in research exploring toxicity in fandom spaces and the gatekeeping behaviors of certain fans. The RCC thus serves as a fascinating case study in how information communities can flourish if toxic behaviors are restricted.

\section{Acknowledgements}

We would like to thank our participants for their time and for sharing their experiences and cosplay journeys with us. We are inspired by all the individuals who spread joy and the Force through cosplaying Rey.

\section{References}

Abercrombie, N., \& Longhurst, B. J. (1998), Audiences: A Sociological Theory of Performance and Imagination, Sage.

Bacon-Smith, C. (1992), Enterprising Women: Television Fandom and the Creation of Popular Myth, University of Pennsylvania Press.

Baker, A. (2012), “The Exchange of Material Culture Among Rock Fans in Online Communities", Information, Communication \& Society, Vol.15 No. 4, pp. 519-536.

Baruah, T.D. (2012), "Effectiveness of Social Media as a Tool of Communication and its Potential for Technology Enabled Connections: A Micro-Level Study", International journal of scientific and research publications, Vol. 2 No. 5, pp. 1-10.

Baym, N. K. (2000), Tune In, Log On: Soaps, Fandom and Online Community, Sage Publications, Inc.

Blanchard, A. L., and Markus, M. L. (2004), “The Experienced 'Sense' of a Virtual Community: Characteristics And Processes”, ACM Sigmis Database, Vol. 35 No. 2, pp. 64-79.

Booth, P. (2016), Digital fandom 2.0, Peter Lang.

Brewer, J. (2000), Ethnography, Open University Press. 
Bullard, J. (2016), "Motivating invisible contributions: Framing volunteer classification design in a fanfiction repository", Proceedings of the $19^{\text {th }}$ International Conference on Supporting Group Work, pp. 181-193.

Campbell, J. A., Aragon, C., Davis, K., Evans, S., Evans, A., and Randall, D. P. (2016), "Thousands of Positive Reviews: Distributed Mentoring in Online Fan Communities", CSCW '16: Proceedings of the 19th ACM Conference on Computer-Supported Cooperative Work \& Social Computing, Association for Computing Machinery, pp. 691704.

Chatman, E. A. (1991), "Life in a Small World: Applicability of Gratification Theory to Information-Seeking Behavior", Journal of the American Society for Information Science, Vol. 42 No. 6, pp. 265-83.

Chatman, E. A. (1996), "The Impoverished Life-World of Outsiders", Journal of the American Society for Information Science, Vol. 37 No. 3, pp. 193-206.

Chatman, E. A. (2000), "Framing Social Life in Theory and Research", New Review of Information Behaviour Research: Studies of Information Seeking in Context, No. 1, pp. 3 17.

Chen, J. (2007), “A Study of Fan Culture: Adolescent Experiences with Animé/Manga Doujinshi and Cosplay in Taiwan”, Visual Arts Research, Vol. 33 No. 1, pp. 14-24.

Christensen, C. M., and Raynor, M. E. (2003), "Why Hard-nosed Executives Should Care about Management Theory”, Harvard Business Review, Vol. 81 No. 9, pp. 66-75.

Click, M. A., and Scott, S. (2017), "Introduction”, In: Click, M. A., and Scott, S. (Eds.), The Routledge Companion to Media Fandom, Routledge, pp. 1-5

Constant, D., Kiesler, S., and Sproull, L. (1994), "What's Mine Is Ours, Or Is It? A Study of Attitudes about Information Sharing”, Information Systems Research, Vol 5 No. 4, pp. 400-421.

De Kosnik, A. (2016), Rogue Archives: Digital Cultural Memory and Media Fandom, The MIT Press.

De Zwart, M. (2013), "Cosplay, Creativity and Immaterial Labours of Love”, In Hunter, D., Lobato, R., Richardson, M., and Thomas, J. (Eds.), Amateur Media: Social, Cultural and Legal Perspectives, Routledge, pp. 170-177.

Dervin, B. (1976), The Development of Strategies for Dealing with the Information Needs of Urban Residents: Phase I-Citizen Study, Vol. 2, University of Washington School of Communication.

Dervin, B., Foreman-Wernet, L., and Lauterbach, E. eds. (2003), Sense-making Methodology Reader: Selected Writings of Brenda Dervin, Hampton Press. 
Di Placido, D. (2017), "Rick and Morty Fans Take Obnoxiousness to a Whole Other Dimension" [online], Forbes, available from:

https://www.forbes.com/sites/danidiplacido/2017/10/08/rick-and-morty-fans-takeobnoxiousness-to-a-whole-new-dimension/\#6d4248aa76ac [Accessed 29 July 2020]

Duffett, M. (2013), Understanding Fandom: An Introduction to the Study of Media Fan Culture, Bloomsbury Academic.

Duggan, M., Lenhart, A., Lampe, C., and Ellison, N. B. (2015), "Parents and Social Media" [online], Pew Research Center, available from: https://www.pewresearch.org/internet/2015/07/16/parents-and-social-media/ [Accessed 2 Feb 2021].

Durrance, J. C., and, Pettigrew, K. (2002), Online Community Information: Creating a Nexus at Your Library, American Library Association.

Evangelista, R. (2019), "Rick and Morty and Toxic Fandom: Factors Contributing to Toxic Communication in the Online Rick and Morty Fan Community", PhD dissertation, Regent University.

Fazel, V., and Geddes, L. (2015). "Give Me Your Hands if We Be Friends': Collaborative Authority in Shakespeare Fan Fiction”, Shakespeare, Vol. 12 No. 3, pp. 274-286.

Fetterman, D. M. (2010), Ethnography: Step-by-step, 3rd ed, Sage Publications.

Feng, J., Preece, J. and Lazar, J. (2003), “Interpersonal Trust and Empathy Online: A Fragile Relationship”, In: CHI'03 Extended Abstracts on Human Factors in Computing Systems, Association for Computing Machinery, pp. 718-719.

Figallo, C. (1998), Hosting Web Communities: Building Relationships, Increasing Customer Loyalty, and Maintaining a Competitive Edge, John Wiley \& Sons, Inc.

Forcier, E. (2017), Re(a)d Wedding: A Case Study Exploring Everyday Information Behaviors of the Transmedia Fan, Proceedings of the Association for Information Science and Technology, Vol. 54 No. 1, pp. 93-101.

Gaudette, E. (2018), What's Wrong with Rick and Morty Fans? How Adult Swim Nerds Became a Meme" [online], Newsweek, available from: https://www.newsweek.com/whats-wrongrick-and-morty-fans-how-adult-swim-nerds-became-meme-824581 [Accessed 29 July 2020].

Geertz, C. (1973), “Thick Description: Toward an Interpretive Theory of Culture”, In: The Interpretation of Cultures: Selected Essays, Basic Books, pp. 3-30.

Hall, H., and Graham, D. (2004), “Creation and Recreation: Motivating Collaboration to Generate Knowledge Capital in Online Communities", International Journal of Information Management, Vol. 24 No. 3, pp. 235-246. 
Hart, C., Schoolbred, M., Butcher, D., \& Kane, D. (1999). The bibliographical structure of fan information. Collection Building, Vol. 18 No. 2, 81-89.

Hartel, J. (2003), "The Serious Leisure Frontier in Library and Information Science: Hobby Domains", Knowledge Organization, Vol. 30 No. 3/4 pp. 228-238.

Hendrickson, M. (2018), “Costumes in Star Wars: The Recreation of Rey's Costume from The Force Awakens", The Measure, Vol. 2, pp. 45-57.

Hill, H., \& Pecoskie, J. J. L. (2017), "Information Activities as Serious Leisure within the Fanfiction Community”, Journal of Documentation, Vol. 73 No. 5, pp. 843-857.

Hill, N. L. (2017), "Embodying Cosplay: Fandom Communities in the USA”, master's thesis, Georgia State University.

Hine, C. (2000), Virtual ethnography, Sage Publications.

Hine, C. (2015), Ethnography for the Internet: Embedded, Embodied and Everyday, Bloomsbury Academic.

History of the Rebel Legion (2015), StarWars.com, available from: https://www.starwars.com/news/history-of-the-rebel-legion-part-1 [Accessed February 2, 2021].

Jenkins, H. (1992), Textual Poachers: Television Fans and Participatory Culture, Routledge.

Jenkins, H. (2006), Convergence Culture, NYU Press.

Jenkins, H. (2007), “Afterword: The Future of Fandom”, In: Gray, J., Sandvoss, C., and Harrington, C. L. (Eds.) Fandom: Identities and Communities in a Mediated World, NYU Press, 357-64.

Jenson, J. (1992), "Fandom as Pathology: The Consequences of Characterization", In: Lewis, L. A. (Ed.), The Adoring Audience: Fan Culture and Popular Media, Routledge, 9-29.

Joinson, Adam N. (2000), "Information Seeking on The Internet: A Study of Soccer Fans on the WWW." CyberPsychology and Behavior, Vol. 3, No. 2, pp. 185-190.

Kim, H. S., Cho, K. M., \& Kim, M. (2019), “Information-sharing Behaviors among Sports Fans Using \#hashtags", Communication \& Sport, available at: https://doi.org/10.1177/2167479519878466 [accessed 15 May 2021].

Kim, M. S., \& Kim, H. M. (2017), "The Effect of Online Fan Community Attributes on the Loyalty and Cooperation of Fan Community Members: The Moderating Role of Connect Hours", Computers in Human Behavior, Vol. 68, pp. 232-243.

Kinsella, S. (2000), Adult Manga: Culture and Power in Contemporary Japanese Society, University of Hawaii Press. 
Lakhani, K. R., and von Hippel, E. (2003), “How Open Source Software Works: 'Free’ User-ToUser Assistance", In: Produktentwicklung mit virtuellen Communities, Gabler Verlag, 303-339.

Lampel, J., and Bhalla, A. (2007), “The Role of Status Seeking in Online Communities: Giving the Gift of Experience", Journal of Computer-Mediated Communication, Vol. 12 No. 2, pp. 434-455.

Lapidot-Lefler, N., and Brak, A. (2012), "Effects of Anonymity, Invisibility, and Lack of Eyecontact on Toxic Online Disinhibition", Computers in Human Behavior, Vol. 28 No. 2, pp. 434-443.

Lewis L. A. (Ed.) (1992), The Adoring Audience: Fan Culture and Popular Media, Routledge.

Lin, S. (2016), Fans, Friends, and Family: An Ethnographic Study of Youths in Singapore's Cosplay Community, Master Thesis, available at: https://core.ac.uk/download/pdf/83108322.pdf [accessed 15 May, 2021].

Mansour, A. (2020), "Shared Information Practices on Facebook: The Formation and Development of a Sustainable Online Community", Journal of Documentation, Vol. 76 No. 3, pp. 625-646.

Mansourian, Y. (2021), "Information Activities in Serious Leisure as a Catalyst for SelfActualisation and Social Engagement", Journal of Documentation (preprint)

McLure, W. M. and Faraj, S. (2000). “'It Is What One Does': Why People Participate and Help Others in Electronic Communities of Practice", The Journal of Strategic Information System, Vol. 9 No. 2-3, pp. 155-173.

Mountfort, P. R., Geczy, A., and Peirson-Smith, A. (2019), Planet Cosplay: Costume Play, Identity and Global Fandom, Intellect.

Murchison, J. (2010), Ethnography Essentials: Designing, Conducting, and Presenting your Research, Jossey-Bass.

Murthy, D. (2008), “Digital Ethnography: An Examination of the Use of New Technologies for Social Research”, Sociology, Vol. 42 No. 5, pp. 837-55.

Nyman, N. (2011), Information Behaviour in World Of Warcraft, Master thesis, available from: https://www.diva-portal.org/smash/get/diva2:394752/FULLTEXT01.pdf. [accessed on 3 May 2021].

Ocepek, M. (2018), "Bringing out the Everyday in Everyday Information Behavior." Journal of Documentation, Vol. 74 No. 2 pp. 398-411. doi:10.1108/JD-10-2016-0119.

Pande, R. (2018), Squee from the Margins: Fandom and Race, University of Iowa Press.

Pendleton, V. E., and Chatman, E. A. (1998), "Small World Lives: Implications for the Public Library”, Library Trends, Vol. 46 No. 4, pp. 732-51. 
Park, J. H., Gu, B., Leung, A. C. M., and Konana, P. (2014), “An Investigation of Information Sharing and Seeking Behaviors in Online Investment Communities", Computers in Human Behavior, Vol 31, pp. 1-12.

Pettigrew, K. E., Durrance, J. C., and Untuh, K. T. (2002), "Facilitation Community Information Seeking Using the Internet: Findings from Three Public Library-Community Network Systems", Journal of the American Society for Information Science and Technology, Vol. 53, No. 11, pp. 894-903.

Pigg, K. E. (2001), “Applications of Community Informatics for Building Community and Enhancing Civic Society”, Information, Communication \& Society, Vol. 4 No. 4, pp. 507-527.

Preece, J. (1999a), “Empathy Online”, Virtual Reality, Vol. 4 No.1, pp. 74-84.

Preece, J. (1999b), "Empathic Communities: Balancing Emotional and Factual Communication", Interacting with Computers, Vol. 12 No. 1, pp. 63-78.

Price, L. (2016), "Review: Rogue archives: Digital cultural memory and media fandom by Abigail De Kosnik" [online], City, University of London Blogs, available from https://blogs.city.ac.uk/ludiprice/2016/12/05/review-rogue-archives-digital-culturalmemory-and-media-fandom-by-abigail-de-kosnik/ [accessed January 28, 2021].

Price L. (2017), Serious Leisure in the Digital World: Exploring the Information Behavior of Fan Communities, $\mathrm{PhD}$ dissertation, City, University of London, available from: https://hcommons.org/deposits/item/hc:16513/ [accessed 15 May 2021].

Price, L., \& Robinson, L. (2017a), "Fan Fiction in the Library", Transformative Works and Cultures, Vol. 25, available from: https://journal.transformativeworks.org/index.php/twc/article/view/1090/895 [accessed 15 May 2021].

Price, L., \& Robinson, L. (2017b), “'Being in a Knowledge Space': Information Behaviour of Cult Media Fan Communities", Journal of Information Science, Vol. 40 No. 5, pp. 649664.

Price, L., \& Robinson, L. (2021), “Tag Analysis as a Tool for Investigating Information Behaviour: Comparing Fan-Tagging on Tumblr, Archive of Our Own and Etsy", Journal of Documentation, Vol. 77 No. 2, 320-358.

Proctor, W. (2017), “'Bitches Ain't Gonna Hunt No Ghosts': Totemic Nostalgia, Toxic Fandom and the Ghostbusters Platonic", Palabra Clave, Vol. 20 No. 4, pp. 1105-1141.

Ridings, C.M. and Gefen, D. (2004), "Virtual Community Attraction: Why People Hang Out Online", Journal of Computer - Mediated Communication, Vol. 10 No. 1, available from: https://doi.org/10.1111/j.1083-6101.2004.tb00229.x [accessed 15 May 2021].

Ridings, C., Gefen, D., \& Arinze, B. (2002), "Some Antecedents and Effects of Trust in Virtual Communities”, Journal of Strategic Information Systems, Vol. 11 No. 3-4, pp. 271-295. 
Savolainen, R. (1995), “Everyday Life Information Seeking: Approaching Information Seeking in the Context of "Way of Life", Library \& Information Science Research, Vol. 17 No. 3, pp. 259-94.

Scott, S. (2019), Fake Geek Girls: Fandom, Gender, and the Convergence Culture Industry, NYU Press.

Shoemaker, P. (1991), Gatekeeping, Sage Publications.

Smock, A., Ellison, N., Lampe, C., and Wohn, D. (2011), "Facebook as a Toolkit: A Uses and Gratification Approach to Unbundling Feature Use", Computers in Human Behavior, Vol 27 No. 6, pp. 2322-2329.

Soegito, A. (2019), "Fans vs. Critics: Challenging Critical Authority through Memes", The Journal of Fandom Studies, Vol. 7 No. 3, pp. 279-301.

Stanfill, M. (2011), "Doing Fandom, (Mis)doing Whiteness: Heteronormativity, Racialization, and the Discursive Construction of Fandom", Transformative Works and Cultures, No. 8.

Stanfill, M. (2018), “The Unbearable Whiteness of Fandom and Fan Studies”, In: Booth, P. (Ed.) A Companion to Media Fandom and Fan Studies, Wiley Blackwell, pp. 305-18.

Stebbins, R. A. (1992), Amateurs, Professionals, and Serious Leisure, McGill-Queen's University Press.

Stebbins, R. A. (2009), "Leisure and Its Relationship to Library and: Information Science: Bridging the Gap.” Library Trends Vol 57 No. 4 pp. 618-31. doi:10.1353/lib.0.0064.

Stokel-Walker, C. (2017), "Rick and Morty Mania: How Toxic Fans Turned a Hit Cartoon into a Hate Movement" [online], The Telegraph, available from: https://www.telegraph.co.uk/on-demand/0/rick-morty-mania-toxic-fans-made-hitcartoon-hate-movement/ [accessed 29 July 2020].

Suler, J. (2000), The Psychology of Cyberspace, Rider University.

Vardell, E., Thomas, P., and Wang, T. (2020), "Information Seeking Behavior of Cosplayers", Proceedings of the Association for Information Science and Technology, Vol 57 No. 1, p. e401.

Vesga Vinchira, Alejandro. (2019), "Modelling the Information Practices of Music Fans Living in Medellín, Colombia", Information Research, Vol. 24 No. 3, p. 833.

Wasko, M. M., \& Faraj, S. (2000). "It is what one does": why people participate and help others in electronic communities of practice. The journal of strategic information systems, 9(23), 155-173.

Wilson, B. and Toku, M. (2004), “'Boys' Love,' Yaoi, and Art Education: Issues of Power and Pedagogy", In: Smith-Shank, D. L. (Ed.), Semiotics and Art/Visual Culture, National Art Education Association Press, pp. 94-103. 
Winge, T. (2006), "Costuming the Imagination: Origins of Anime and Manga Cosplay", Mechademia, No. 1, pp. 65-76.

Wood, R., Litherland, B., and Reed, E. (2019), "Girls Being Rey: Ethical Cultural Consumption, Families and Popular Feminism”, Cultural Studies, Vol. 34 No. 4, pp. 546-566. 